\title{
Loss of Prolyl-Hydroxylase 1 Protects against Biliary Fibrosis via Attenuated Activation of Hepatic Stellate Cells
}

Moritz J. Strowitzki, ${ }^{*}$ Johanna Kirchberg, ${ }^{*}$ Christopher Tuffs, ${ }^{*}$ Maximilian Schiedeck, ${ }^{*}$ Alina S. Ritter, ${ }^{*}$ Marvin Biller, ${ }^{*}$ Jonathan M. Harnoss, ${ }^{*}$ Felix Lasitschka, ${ }^{\dagger}$ Thomas Schmidt, ${ }^{*}$ Praveen Radhakrishnan, ${ }^{*}$ Alexis Ulrich, ${ }^{*}$ and Martin Schneider*

From the Department of General, Visceral and Transplantation Surgery, ${ }^{*}$ and the Institute of Pathology, ${ }^{\dagger}$ University Hospital Heidelberg, Heidelberg, Germany

Accepted for publication August 14, 2018.

Address correspondence to Martin Schneider, M.D., Department of General, Visceral and Transplantation Surgery, University of Heidelberg, Im Neuenheimer Feld 110, D-69120 Heidelberg, Germany. E-mail: m.schneider@uni-heidelberg. de.

\begin{abstract}
Liver fibrosis, eventually progressing to cirrhosis necessitating liver transplantation, poses a significant clinical problem. 0xygen shortage (hypoxia) and hypoxia-inducible transcription factors (HIFs) have been acknowledged as important drivers of liver fibrosis. The significance of oxygen-sensing HIF prolylhydroxylase (PHD) enzymes in this context has, however, remained elusive. In this study, we demonstrate that loss of PHD1 $\left(\mathrm{PHD}^{-/-}\right)$attenuates the development of liver fibrosis in mice subjected to chronic bile duct injury, induced by 3,5-diethoxycarbonyl-1,4-dihydrocollidine. This effect was accompanied with reduced recruitment of inflammatory leukocytes and attenuated occurrence of profibrotic myofibroblasts in PHD1 ${ }^{-/}$livers. Further analyses focused on the significance of PHD1 in the activation of hepatic stellate cells (HSCs), which represent the driving force in liver fibrosis. Primary HSCs isolated from $\mathrm{PHD}^{-/-}$mice displayed significantly attenuated myofibroblast differentiation and profibrogenic properties compared with HSCs isolated from wild-type mice. Consistently, the expression of various profibrogenic and promitogenic factors was reduced in $\mathrm{PHD}^{-/-} \mathrm{HSCs}$, without alterations in HIF-1 $\alpha$ protein levels. Of importance, PHD1 protein was expressed in HSCs within human livers, and PHD1 transcript expression was significantly increased with disease severity in hepatic tissue from patients with liver fibrosis. Collectively, these findings indicate that PHD1 deficiency protects against liver fibrosis and that these effects are partly due to attenuated activation of HSCs. PHD1 may represent a therapeutic target to alleviate liver fibrosis. (Am J Pathol 2018, 188: 2826-2838; https://doi.org/ 10.1016/j.ajpath.2018.08.003)
\end{abstract}

Liver cirrhosis accounts for approximately $60 \%$ of all indications for liver transplantation. Thus, there is a tremendous need for innovative therapeutic approaches to prevent progression from reversible liver fibrosis to liver cirrhosis and eventually liver cancer. ${ }^{1,2}$ Liver fibrosis is characterized by excess deposition of extracellular matrix within hepatic parenchyma. ${ }^{1}$ This process is crucially triggered by hepatic stellate cells (HSCs), which become activated by cytokines such as profibrogenic transforming growth factor (TGF)- $\beta$ to form myofibroblasts. ${ }^{3,4}$ In mice, these processes can be experimentally induced by feeding with xenobiotics such as 3,5-diethoxycarbonyl-1,4-dihydrocollidine (DDC)., 5,6

Several studies have highlighted the significance of hypoxia in the development of liver fibrosis after chronic injury. $^{7-9}$ The effects of hypoxia on cells and organs are crucially mediated by hypoxia-inducible transcription factors (HIF-1 $\alpha$, HIF-2 $\alpha$ ), which are continuously degraded under normoxia but stabilized in hypoxic conditions. ${ }^{10-12}$ HIF prolyl-hydroxylase domain-containing enzymes (PHD1, PHD2, and PHD3) are molecular oxygen sensors

Supported by the German Federal Ministry of Education and Research (BMBF) grant $031 \mathrm{~L} 0084$ (M.S.), the German Research Foundation (DFG) grants SCHN 947/4-2 (M.S.) and STR 1570/1-1 (M.J.S.), and the Braun Foundation grant BBST-D-18-00018 (M.J.S.).

Disclosures: None declared.

Current address of J.K., Department of Visceral, Thoracic and Vascular Surgery, University Hospital Dresden, Dresden, Germany. 
that regulate the activity of HIFs and other (yet only partly identified) molecular targets. The three PHD enzymes exert specific and nonredundant functions and are implicated in various pathologic disorders characterized by hypoxia. ${ }^{13,14}$ The expression of HIF- $1 \alpha$ increases gradually with the severity of liver fibrosis, ${ }^{15,16}$ and the significance of HIF- $1 \alpha$ in the pathogenesis of liver fibrosis has been well documented. ${ }^{8,16}$ Specific functions of the HIF-PHD enzymes in this context are, by contrast, widely unknown.

However, several reports have highlighted a specific role of PHD1 in liver pathology. ${ }^{17}$ Loss of PHD1 reduces the oxygen consumption of hepatocytes exposed to ischemia, thus increasing their hypoxia tolerance and protecting liver tissue against ischemic damage. ${ }^{18}$ PHD1 deficiency likewise enhances hepatocyte proliferation and liver regeneration after partial hepatectomy. ${ }^{19}$ Of interest, this effect can be mimicked by treatment with pharmacologic PHD enzyme inhibitors. $^{19-21}$

Given these specific functions of PHD1 in the liver, we aimed to assess the significance of PHD1 in the pathogenesis of liver fibrosis, applying a mouse model of biliary fibrosis.

\section{Materials and Methods}

\section{Animal Models}

All animal experiments were approved by the ethical commission of the local government and conducted under the NIH's Guide for the Care and Use of Laboratory Animals. ${ }^{22}$ The generation of PHD1 knockout mice has been described elsewhere. $^{23}$ Wild-type (WT), globally PHD1-deficient $\left(\mathrm{PHD}^{-l-}\right)$, PHD2-deficient $\left(\mathrm{PHD} 2^{+l-}\right)$, and PHD3deficient $\left(\mathrm{PHD}^{-1-}\right.$ ) mice aged 10 to 12 weeks were used for experiments. Mice were treated with DDC ( $2.5 \mathrm{mg}$ p.o. diluted in $2 \mathrm{~mL} / \mathrm{kg}$ body weight corn oil 2 times/week) or vehicle (corn oil, $2 \mathrm{~mL} / \mathrm{kg}$ body weight 2 times/week) for 42 days. Mice were sacrificed 6 weeks after initial treatment under anesthesia to harvest livers and blood samples under standardized conditions for further examination.

\section{Histology and Immunohistochemistry}

Paraffin-embedded liver sections were routinely stained with hematoxylin and eosin (Merck, Darmstadt, Germany). Histomorphometric quantification of cirrhotic liver areas was performed by applying computer-assisted image analysis of 12 standardized high-power fields per specimen by two individual investigators using Zeiss KS300 morphometry software (Zeiss, Jena, Germany) and was expressed as percentage of the total parenchymal area. Porphyrin pigment plugs were counted in 12 high-power fields per section by two individual investigators of hematoxylin and eosin-stained liver sections. ${ }^{6}$ Masson-Trichrome-Goldner staining (Merck) was conducted to dye collagen fibers. For immunohistochemical staining of paraffin tissue, antigens were retrieved with Target Retrieval Solution (Dako, Hamburg, Germany) and blocked with serum (Vector Laboratories, Burlingame, CA) with dilution of 1:5 in Tris-NaCl-blocking buffer. Primary antibody was incubated overnight at $4^{\circ} \mathrm{C}$. The following primary antibodies were used: CD45 (dilution 1:50; BD Pharmigen, San Jose, CA), $\alpha$-smooth muscle actin ( $\alpha$-SMA; dilution 1:200; Abcam, Cambridge, UK), and Desmin (dilution 1:200; Abcam). Appropriate secondary antibodies (Vector Laboratories) were added at dilution of 1:200 in 1.5\% bovine serum albumin/phosphate-buffered saline and visualized with 3,3'-diaminobenzidine (Dako). Stained sections were analyzed by counting the total number of stained cells within 25 high-power fields. For double staining of human liver samples EnVision Doublestain System (Dako) was applied with PHD1 (dilution 1:100; Thermo Fisher, Mannheim, Germany) and $\alpha$-SMA (dilution 1:100; Abcam) as primary antibodies.

For immunocytochemistry of isolated murine HSCs, cells were grown on coverslips, blocked with $3 \%$ bovine serum albumin/phosphate-buffered saline, and incubated with primary antibody overnight with the use of the following dilutions: $\alpha$-SMA (dilution 1:100; Abcam), glial fibrillary acidic protein-cyanine 3 (dilution 1:300; Abcam), PHD1 (dilution 1:100; Abcam), PHD2 (dilution 1:50; NovusBiologicals, Littleton, CO), and PHD3 (dilution 1:50; Abcam). For unconjugated antibodies appropriate secondary antibodies (dilution 1:100; Sigma-Aldrich, Taufkirchen, Germany) were added the next day, before mounting with Prolong Gold with DAPI (Thermo Fisher).

\section{Quantitative Real-Time PCR}

Total RNA was isolated from cells by using the RNeasy Mini Kit (Qiagen, Hilden, Germany). Human paraffinembedded liver tissue samples were deparaffinized by quenching in xylene (Carl Roth $\mathrm{GmbH}$, Karlsruhe, Germany) before conducting RNA isolation by using the RNAqueous-Micro Kit (Life Technologies, Carlsbad, CA). ${ }^{24}$ Reverse transcription was performed with ImProm-II Reverse Transcription System (Promega Corporation, Madison, WI) and quantitative RT-PCR (RT-qPCR) was conducted by using the LightCycler 480 SYBR Green I Master Mix Kit (Roche, Mannheim, Germany), applying specific primers (Table 1). 185 was used as housekeeping gene.

\section{Cell Culture Experiments}

Primary HSCs were isolated from livers of mice by a modified two-step collagenase perfusion as described previously. ${ }^{25}$ Briefly, a 22-gauge cannula was inserted into the portal vein. The liver was then perfused at $10 \mathrm{~mL} /$ minute with wash solution (Gey's balanced salt solution; SigmaAldrich) until completely pale. Afterward the liver was perfused at $5 \mathrm{~mL} /$ minute with digestion solution (Gey's 
Table 1 mRNA Primer Sequences for Quantitative RT-PCR

\begin{tabular}{|c|c|c|c|}
\hline Gene & Synonym & Forward sequence & Reverse sequence \\
\hline Acta2 & $\alpha-S M A$ & 5'-TCСTCССTGGAGAAGAGCTAC-3' & $5^{\prime}$-ATAGGTGGTTTCGTGGATGC- $3^{\prime}$ \\
\hline Col1a1 & Collagen I $\alpha$ & $5^{\prime}$-CACCTATCACTGCAAGAACAGC- $3^{\prime}$ & 5'-GACTGTCTTGCCCCAAGTTC-3' \\
\hline Cxcl10 & CXCL-10 & $5^{\prime}$-CCACGTGTTGAGATCATTGC-3' & 5'-TGGCTTCACTCCAGTTAAGGAG-3' \\
\hline Pdgf & PDGF & $5^{\prime}$-GCACCGAAAGTTTAAGCACAC-3' & 5'-GGGGCAATACAGCAAATACC-3' \\
\hline P4ha1 & P4HA1 & $5^{\prime}$-GAGCCGAGCTACAGTACATGA-3' & 5'-GCCAAGCACTCTTAGATACTCTGT-3' \\
\hline EGLN1 & PHD2 & 5'-CGACCTGATACGCCACTGTA-3' & 5'-CCTTGGCATCCCAGTCTTTA-3' \\
\hline EGLN3 & PHD3 & $5^{\prime}$-AGATCGTAGGAACCCACACG-3' & $5^{\prime}$-CAGATTTCAGAGCACGGTCA-3' \\
\hline Il6 & IL-6 & $5^{\prime}$-ACAAAGCCAGAGTCCTTCAGAG-3' & 5'-тCСТTAGCCACTCСTTCTGTG-3' \\
\hline Tgfb1 & TGF- $\beta 1$ & $5^{\prime}-$ TCCAAACAGATGGCAGAGC $-3^{\prime}$ & 5'-TTCCTGTTGGCTGAGTTGTG-3' \\
\hline $\operatorname{Tnf}$ & TNF $\alpha$ & $5^{\prime}$-GGCATGGATCTCAAAGACAACC-3' & 5'-CAGGTATATGGGCTCATACCAG-3' \\
\hline
\end{tabular}

$\alpha$-SMA, $\alpha$-smooth muscle actin; CTGF, connective tissue growth factor; CXCL-10, chemokine (C-X-C motif) ligand 10; IL-6, interleukin-6; P4HA, prolylhydroxylase alpha; PAI, plasminogen activator inhibitor; PDGF, platelet-derived growth factor; PHD, HIF prolyl-hydroxylase domain-containing enzyme; TGF; transforming growth factor; TNF, tumor necrosis factor; VEGF, vascular endothelial growth factor.

balanced salt solution with $\mathrm{Ca}^{2+}$ and collagenase IV; Sigma-Aldrich). After the two-step collagenase perfusion the liver was excised, digested with DNAse 1 solution (DNAse 1: $30 \mu \mathrm{g} / \mathrm{mL}, 1 \mathrm{~mol} / \mathrm{L}$ HEPES $0.5 \mathrm{~mL}$; SigmaAldrich) and minced to prepare a cell suspension, which was subsequently repeatedly passed through a $100-\mu \mathrm{m}$ cell strainer. The single-cell suspension was differentially centrifuged and resuspended, applying OptiPrep density gradient medium (Sigma-Aldrich) several times to isolate HSCs. HSCs were cultured in Dulbecco's modified Eagle's medium (Sigma-Aldrich) with $10 \%$ fetal bovine serum (Sigma-Aldrich), $1 \%$ penicillin/streptomycin (SigmaAldrich), and $10 \mathrm{mmol} / \mathrm{L}$ HEPES.

NIH-3T3 murine embryonic fibroblasts were purchased from the ATCC (LGC Standards GmbH, Wesel, Germany) and cultured in Dulbecco's modified Eagle's medium supplemented with $10 \%$ fetal calf serum (Gibco, Darmstadt, Germany) and $1 \%$ penicillin/streptomycin at $37^{\circ} \mathrm{C}$ and $5 \%$ $\mathrm{CO}_{2}$. LX-2 human HSCs were obtained from Merck and maintained in Dulbecco's modified Eagle's medium with 2\% fetal calf serum and $1 \%$ penicillin/streptomycin. RNA interference was conducted by using Lipofectamine2000 (Invitrogen, Darmstadt, Germany) and a PHD1-specific siRNA (Flexi Tube Gene solution; Qiagen), resulting in effective silencing of PHD1 (residual PHD1 mRNA expression levels in siPHD1-treated LX-2 cells: $24.37 \% \pm 5.38 \%$ of levels in control-transfected cells; $P=0.001 ; n=3$ ). Transfected cells were starved overnight before performing an invasion assay by using a Matrigelcoated Boyden chamber (Greiner Bio-One, Kremsmünster, Austria) with fetal calf serum as chemoattractant. Invading cells were quantified by dissolving cell-bound crystal violet (Sigma-Aldrich) in 10\% acetic acid (Carl Roth $\mathrm{GmbH}$ ) and measuring the optical density at $540 \mathrm{~nm}$. All cell culture experiments were performed in triplicates.

\section{Detection of HIF-1 $\alpha$ Protein Levels}

For quantification of HIF- $1 \alpha$ protein levels a commercially available enzyme-linked immunosorbent assay kit (Abcam) was used to detect DNA binding activity. HIF- $1 \alpha$ levels were assessed by using nuclear extracts from primary isolated HSCs of $\mathrm{PHD}^{-l-}$ and WT mice under normoxic (21\% oxygen) culture conditions and after hypoxia exposure ( $0.75 \%$ oxygen). In addition, HIF- $1 \alpha$ levels were determined in liver lysates from $\mathrm{PHD}^{-1-}$ and WT mice under baseline conditions and after DDC exposure. Absorbance was measured at $450 \mathrm{~nm}$. All experiments were performed in accordance with the instructions provided by the manufacturer and in triplicates.

\section{Human Liver Samples}

Tissue samples were provided by the tissue bank of the National Center of Tumor Diseases (NCT, Heidelberg, Germany) in accordance with the regulations of the tissue bank and approval of the ethics committee of the University of Heidelberg. In total, 81 specimens were analyzed. Histomorphologic changes of human liver samples were classified according to the Desmet score for staging of fibrosis in chronic hepatitis (Desmet score 0, no fibrosis, up to Desmet score 4, cirrhosis). ${ }^{26}$

\section{Statistical Analysis}

All values are represented as arithmetic means \pm SEM. Group differences were evaluated by two-tailed $t$-test or analysis of variance, followed by an appropriate post hoc test, including Bonferroni probabilities to compensate for multiple comparisons by using GraphPad Prism5 (GraphPad Software, La Jolla, CA) and Excel 2013 (Microsoft, Redman, WA). Overall statistical significance was set at $P<0.05$. 


\section{Results}

\section{Loss of PHD1 Attenuates Biliary Fibrosis in Vivo}

To determine the significance of PHD1 in liver fibrosis, WT and $\mathrm{PHD}^{-1-}$ mice were exposed to an experimental animal model of biliary liver fibrosis, induced by feeding with DDC for 6 weeks. ${ }^{6}$ Microscopic analysis of liver sections stained with hematoxylin and eosin and Masson-TrichromeGoldner histochemistry revealed normal appearance of WT and PHD1 ${ }^{-1-}$ livers at baseline conditions before DDC feeding (Figure 1, A and B). DDC exposure expectedly induced fibrotic deposits around the portal triads of WT livers (Figure 1, A and B). However, the extent of periportal fibrosis was strikingly reduced in DDC-treated PHD $1^{-/-}$ mice (Figure 1, A and B). Morphometric quantification of fibrotic tissue areas confirmed a significant reduction of fibrotic tissue areas in livers from PHD $1^{-l-}$ mice exposed to DDC (Figure 1C), which was not present in mice deficient for PHD2 $\left(\mathrm{PHD}^{+/-}\right)$or PHD3 $\left(\mathrm{PHD}^{-/-}\right)$. At baseline conditions, periportal connective tissue areas tended to be slightly (but nonsignificantly) smaller in $\mathrm{PHD}^{-1-}$ than in WT livers.
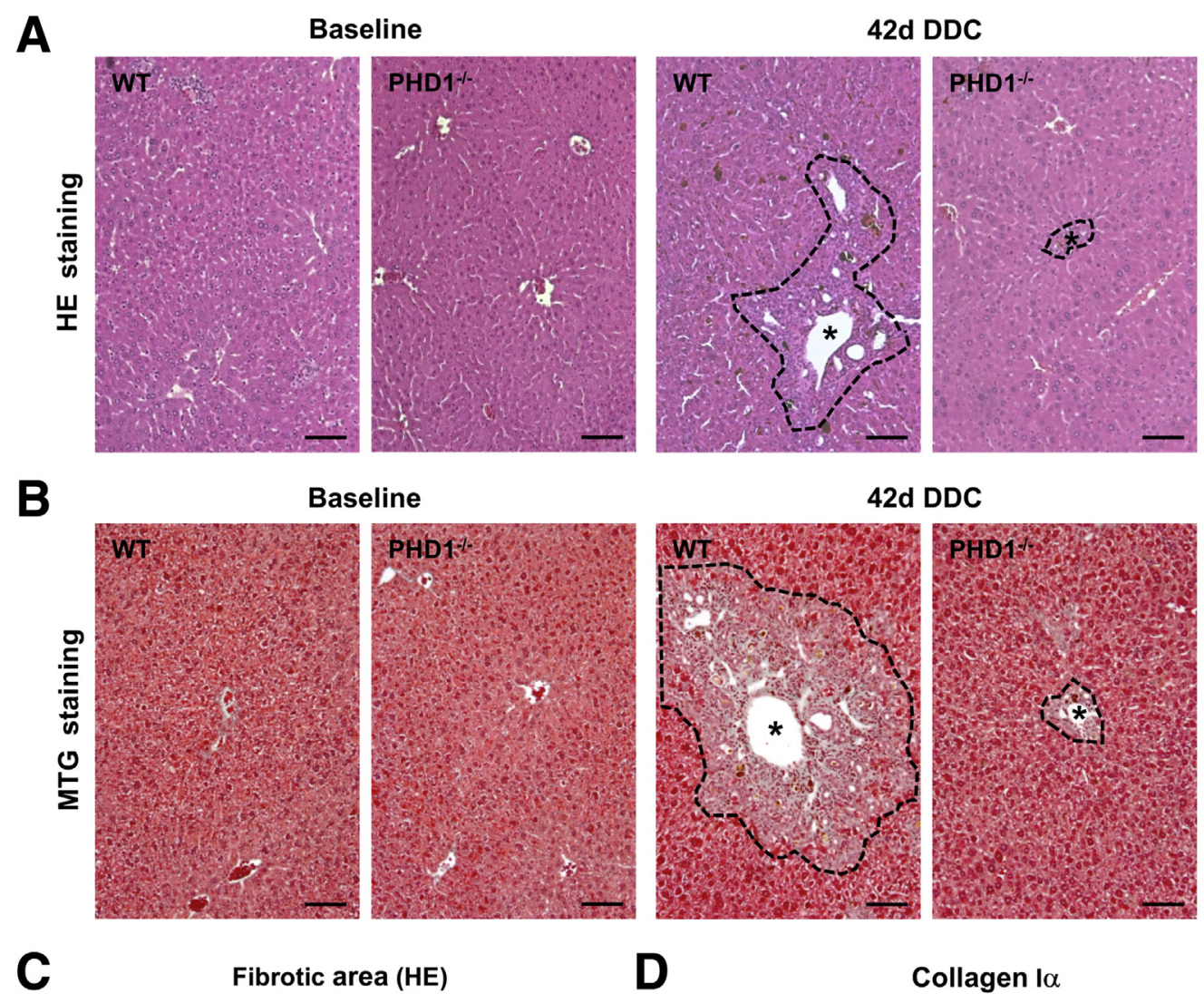

Fibrotic area (HE)
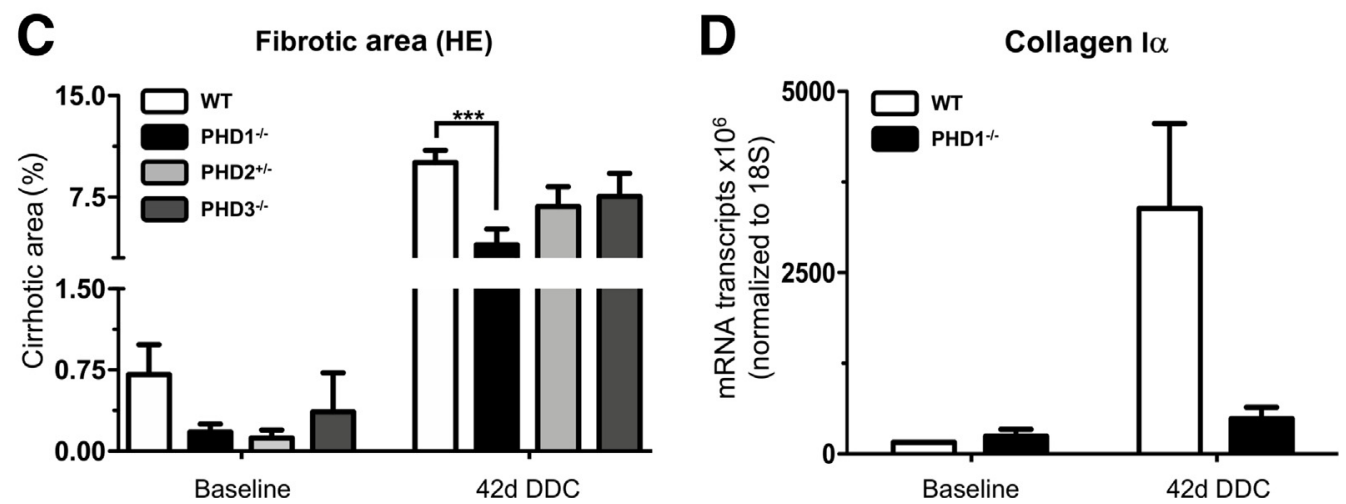

Figure 1 Loss of prolyl-hydroxylase 1 (PHD1) protects mice against 3,5-diethoxycarbonyl-1,4-dihydrocollidine (DDC)-induced fibrosis. A and B: Representative images of hematoxylin and eosin (HE) (A) and Masson-Trichrome-Goldner (MTG) staining (B) of wild-type (WT) and PHD1 ${ }^{-/-}$livers at baseline conditions and after treatment with DDC for 42 days. Note markedly reduced periportal fibrotic areas (dashed lines) in DDC-treated PHD1 ${ }^{-/-}$mice compared with WT animals. Asterisks depict portal vein branches. C: Quantification of fibrotic areas in livers from WT, $\mathrm{PHD}^{-/-}, \mathrm{PHD}^{+/-}$, and PHD3 ${ }^{-/-}$mice revealed the extent of periportal fibrotic areas in baseline conditions and after DDC treatment. D: Quantitative RT-PCR analysis revealed marked reduction of collagen I $\alpha$ expression in liver lysates from PHD1 ${ }^{-/}$mice but not from WT mice treated with DDC. Data are expressed as means \pm SEM. $n=8$ mice in each group (A-C); $n=5$ mice per group (D). ${ }^{* *} P<0.001$. Scale bars $=100 \mu \mathrm{m}(\mathbf{A}$ and $\mathbf{B})$. 
The hepatic expression of type I $\alpha$ collagen was assessed as an alternative readout of liver fibrosis in DCC-treated mice. Consistent with the histologic findings outlined above, RT-qPCR of whole liver lysates revealed attenuated abundance of collagen $\mathrm{I} \alpha$ transcripts in $\mathrm{PHD} 1^{-/-}$mice compared with WT mice treated with DDC (Figure 1D). At baseline conditions, however, collagen expression did not differ between $\mathrm{PHD}^{-/-}$and WT livers.

Serum markers of liver injury were determined to assess the extent of DDC-induced liver damage in WT and $\mathrm{PHD}^{-/-}$mice. DDC treatment expectedly increased serum levels of lactate dehydrogenase, glutamic oxaloacetic transaminase, and glutamic pyruvic transaminase compared with baseline conditions (Table 2). This DDC-induced increase in serum lactate dehydrogenase, glutamic oxaloacetic transaminase, and glutamic pyruvic transaminase levels was, however, significantly attenuated in $\mathrm{PHD}^{-/-}$mice (Table 2). Serum levels of alkaline phosphatase, a marker of biliary obstruction, were likewise increased in DDC-treated animals but not significantly altered in $\mathrm{PHD}^{-/-}$mice (Table 2). Variables that indicated hepatic protein synthesis, such as albumin or choline esterase, remained unaffected by DDC treatment or loss of PHD1 gene function (Table 2).

Development of biliary fibrosis in the DDC model was triggered by biliary porphyrin secretion. ${ }^{6}$ Of note, histomorphologic analysis revealed that the abundance of intraductal porphyrin pigment plugs in periportal fields was significantly attenuated in livers from DDC-treated $\mathrm{PHD}^{-1-}$ mice compared with their WT littermates (Supplemental Figure S1, A and B). To assess whether this was due to putative effects of PHD1 deficiency on iron homeostasis, plasma levels of iron and transferrin were likewise analyzed. Markers of iron homeostasis were, however, unaltered in PHD1 $1^{-/-}$mice at baseline conditions and after DDC exposure (Supplemental Figure S1, C and D, and Table 2). Consistently, enzyme-linked immunosorbent assays revealed comparable HIF-1 $\alpha$ protein levels in liver lysates from WT and $\mathrm{PHD}^{-/-}$mice (Supplemental Figure S1E).

Collectively, these results indicated a striking HIF1 -independent protection of $\mathrm{PHD}^{-1-}$ mice against liver fibrosis in a murine model of biliary fibrosis.

\section{Loss of PHD1 Reduces Leukocyte- and Myofibroblast- Infiltration after DDC Treatment}

Biliary fibrosis was crucially triggered by interactions between infiltrating leukocytes $\left(\mathrm{CD}^{4} 5^{+}\right.$cells) and $\mathrm{HSCs}$, which become activated by cytokines such as TGF- $\beta$ to form myofibroblasts. ${ }^{5,6}$ Immunohistochemistry and morphometric quantification were performed to determine the effects of PHD1 deficiency on the abundance of these cells in livers from healthy and DDC-treated mice. At baseline conditions, the abundance of $\mathrm{CD} 45^{+}$leukocytes was similarly low in WT and PHD1 ${ }^{-1-}$ livers (Figure 2, A and B). DDC treatment led to marked accumulation of infiltrating leukocytes in periportal regions of WT livers, which was almost absent in livers from $\mathrm{PHD}^{-1-}$ mice exposed to DDC (Figure 2, A and B). $\alpha$-SMA immunostaining was applied to assess the abundance of hepatic myofibroblasts. $^{27}$ At baseline conditions, $\alpha$-SMA expression within periportal areas was mostly restricted to the vascular smooth muscle cells of larger vessels in both WT and PHD $^{-l-}$ mice (Figure 2C). After DDC exposure, multiple $\alpha$-SMA-positive myofibroblasts were detected in

Table 2 Plasma Concentrations of Liver Function Variables in Mice at Baseline Conditions and after 42 Hours of DDC Treatment $(n=8$ in each group)

\begin{tabular}{|c|c|c|c|c|c|c|}
\hline \multirow[b]{2}{*}{ Plasma value } & \multicolumn{2}{|c|}{ Baseline, means \pm SEM } & \multirow[b]{2}{*}{$P$ value* } & \multicolumn{2}{|c|}{ 42d DDC, means \pm SEM } & \multirow[b]{2}{*}{$P$ value* } \\
\hline & WT & $\mathrm{PHD}^{-/-}$ & & WT & $\mathrm{PHD}^{-/-}$ & \\
\hline \multicolumn{7}{|l|}{ Liver injury } \\
\hline GOT, U/L & $65.0 \pm 30.4$ & $27.8 \pm 3.6$ & 0.210 & $534.3 \pm 82.6$ & $316.5 \pm 46.8$ & 0.036 \\
\hline GPT, U/L & $25.8 \pm 3.3$ & $25.7 \pm 2.5$ & 0.970 & $234.8 \pm 69.9$ & $102.1 \pm 11.6$ & 0.087 \\
\hline \multicolumn{7}{|l|}{ Biliary damage } \\
\hline $\mathrm{ChE}, \mathrm{kU} / \mathrm{L}$ & $2.9 \pm 0.5$ & $2.9 \pm 0.4$ & 0.960 & $3.2 \pm 0.2$ & $3.8 \pm 0.4$ & 0.260 \\
\hline Albumin, $\mathrm{g} / \mathrm{L}$ & $13.7 \pm 0.5$ & $15.7 \pm 0.3$ & 0.008 & $17.5 \pm 0.7$ & $16.9 \pm 0.7$ & 0.560 \\
\hline \multicolumn{7}{|l|}{ Blood count } \\
\hline Leukocytes, /nL & $2.9 \pm 0.5$ & $3.3 \pm 0.4$ & 0.540 & $5.5 \pm 0.5$ & $4.6 \pm 0.3$ & 0.120 \\
\hline Erythrocytes, /pL & $8.6 \pm 0.5$ & $9.4 \pm 0.7$ & 0.342 & $9.2 \pm 1.1$ & $9.6 \pm 0.5$ & 0.6848 \\
\hline
\end{tabular}

*Determined by $t$-test.

AP, alkaline phosphatase; ChE, cholinesterase; DDC, 3,5-diethoxycarbonyl-1,4-dihydrocollidine; GOT, glutamic oxaloacetic transaminase; GPT, glutamic pyruvic transaminase; LDH, lactate dehydrogenase; WT, wild-type. 

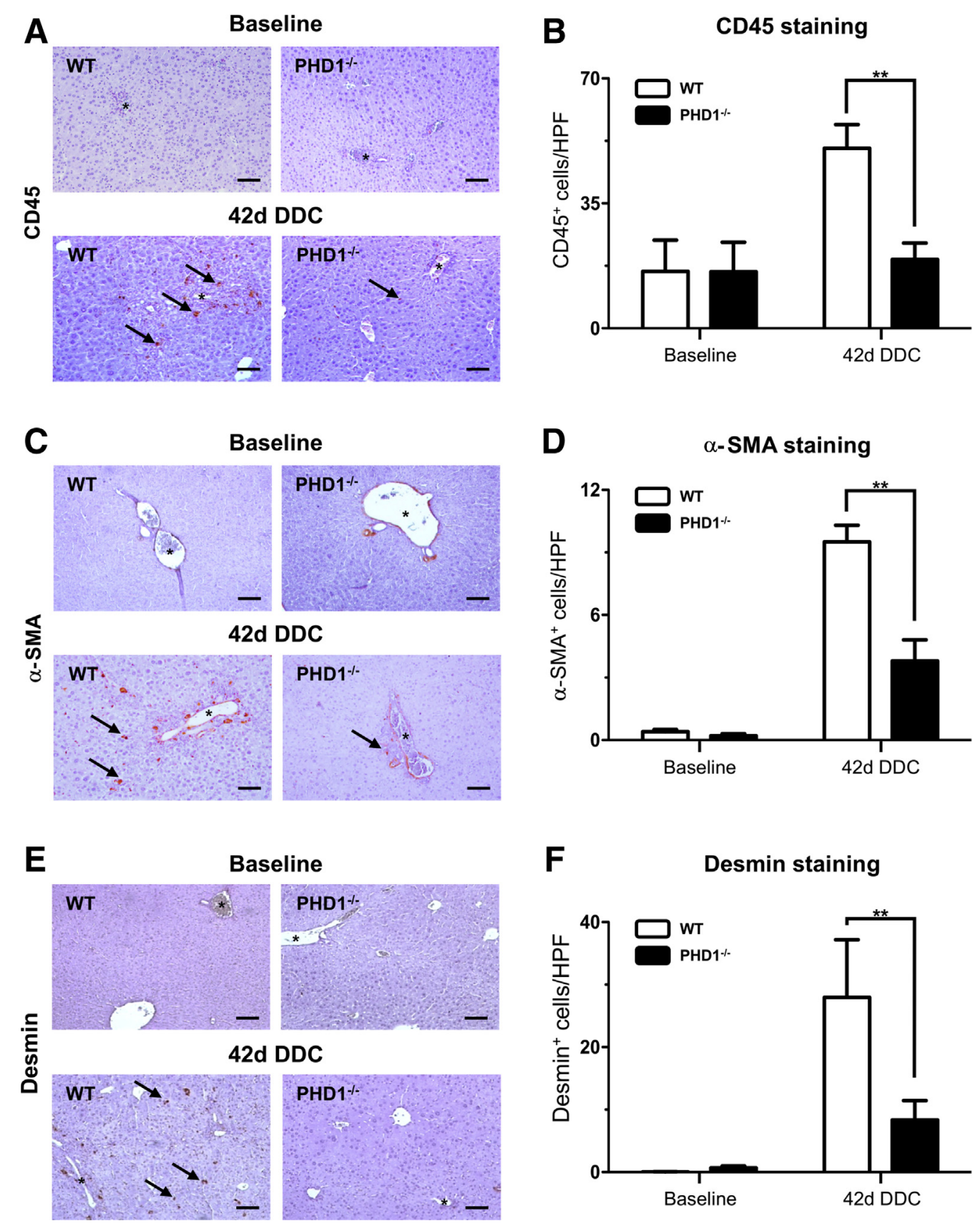

Figure 2 Attenuated leukocyte and myofibroblast infiltration in livers from 3,5-diethoxycarbonyl-1,4-dihydrocollidine (DDC)-treated prolyl-hydroxylase 1-deficient (PHD1 ${ }^{-1-}$ ) mice. A and B: Representative images of CD45 immunostaining (A) and histomorphometric quantification (B) of leukocytes (arrows) in livers from wild-type (WT) or PHD1 ${ }^{-1-}$ mice at baseline conditions and after DDC treatment for 42 days (A). C and D: Representative images of $\alpha$ smooth muscle actin ( $\alpha$-SMA) immunostaining (C) and histomorphometric quantification (D) of myofibroblasts (arrows) in livers from WT or PHD1 ${ }^{-/-}$mice at baseline conditions and after DDC treatment for 42 days (C). E and F: Representative images of desmin immunostaining (E) and histomorphometric quantification (F) of hepatic stellate cells (HSCs) and fibroblasts (arrows) in livers from WT or PHD1 ${ }^{-1-}$ mice at baseline conditions and after DDC treatment for 42 days (E). Asterisks in A, C, and $\mathbf{E}$ depict portal branches. Data are expressed as means \pm SEM. $n=5$ mice in each group. ${ }^{* *} P<0.01$. Scale bars $=100 \mu \mathrm{m}$ (A, C, and E). HPF, high-power field.

periportal regions of WT livers (Figure 2C). However, the abundance of $\alpha$-SMA-positive myofibroblasts in livers from DDC-treated PHD $1^{-1-}$ mice was strikingly lower than in those from their WT counterparts (Figure 2, C and D). In addition, desmin immunostaining was performed to label HSCs and fibroblasts in murine livers. ${ }^{28}$ Consistent with the reduced occurrence of $\alpha$-SMA-positive myofibrobasts, the abundance of desmin-positive HSCs and fibroblasts was likewise significantly reduced in livers of $\mathrm{PHD}^{-1-}$ mice exposed to DDC (Figure 2, E and F).

Taken together, alleviated development of biliary fibrosis in $\mathrm{PHD}^{-l-}$ mice occurred concomitantly with reduced 
recruitment of inflammatory leukocytes and markedly attenuated occurrence of profibrotic myofibroblasts in periportal areas.

\section{Loss of PHD1 Attenuates the Profibrogenic Activation of HSCS}

HSCs contributed an important source of myofibroblasts, which triggered biliary fibrogenesis. ${ }^{5}$ It was therefore investigated whether loss of PHD1 altered the fibrogenic potential of HSCs.

The expression of the different HIF-PHD enzymes in HSCs was first assessed. Indeed, RT-qPCR revealed that PHD1 represented the most abundantly expressed PHD enzyme in the immortalized human HSC line LX-2 (Figure 3A). ${ }^{29}$ Immunocytochemistry was likewise performed and confirmed the expression of PHD1 protein in LX-2 HSCs, whereas PHD2 and PHD3 protein appeared to be only faintly expressed (Figure 3B).

To determine the functional relevance of PHD1 in fibrogenesis triggered by HSCs, primary cultures of HSCs, isolated from WT and $\mathrm{PHD}^{-1-}$ mice, were established. No morphologic differences were apparent between WT and $\mathrm{PHD}^{-1-}$ HSCs cultured for 1 day (Figure 3C). Likewise, immunocytochemistry revealed comparable expression of glial fibrillary acidic protein, a marker labeling un-activated HSCs, ${ }^{30}$ in WT and PHD $1^{-1-}$ HSCs after 1 day in culture (Figure 3C). After 5 days in culture, however, $\mathrm{PHD}^{-1-}$ HSCs appeared significantly less enlarged and formed less pseudopodia than their WT counterparts (Figure 3D). Consistently, immunocytochemistry revealed reduced expression of $\alpha$-SMA, a marker labeling activated HSCs and myofibroblasts, ${ }^{27}$ in PHD1 ${ }^{-1-}$ HSCs cultured for 7 days (Figure 3D), collectively indicating attenuated activation and myofibroblast differentiation of PHD1deficient HSCs.

It was also assessed whether PHD1 deficiency impaired the motility of fibrogenic cells. Because myofibroblast differentiation of $\mathrm{PHD}^{-1-}$ HSCs was significantly delayed (see above), these experiments were performed, applying primary mouse embryonic fibroblasts harvested from WT and $\mathrm{PHD}^{-1-}$ mice. Matrigel invasion assays revealed significantly impaired invasive potential of PHD $^{-1-}$ mouse embryonic fibroblasts compared with WT cells on stimulation with fetal calf serum (Figure 3E). Comparable results were obtained when performing siRNA-mediated knockdown of PHD1 in the commercially available mouse fibroblast cell line NIH3T3 or the human HSC line LX-2. Indeed, knockdown of PHD1 significantly impaired the invasive potential of NIH3T3 fibroblasts (Figure 3E) or LX-2 HSCs (Figure 3E) compared with control-treated cells.

Taken together, these findings indicated that loss of PHD1 attenuated myofibroblast differentiation and profibrogenic properties of HSCs.
Molecular Mediators of HSC Activation Affected by PHD1 Deficiency

RT-qPCR-based expression analysis of various profibrogenic and promitogenic factors was performed to substantiate the effects of PHD1 deficiency on HSC activation on the molecular level. Transcript expression levels of connective tissue growth factor, TGF- $\beta 1$, platelet-derived growth factor, CXCL-10, IL-6, and tumor necrosis factor $\alpha$, all of which are autocrine drivers of HSC activation, invasion, proliferation, or transdifferentiation to myofibroblasts, ${ }^{4,31-33}$ were lower in PHD $1^{-1-}$ HSCs than in corresponding WT cells maintained in culture for 7 days (Figure 4A). The same held true for the myofibroblast markers, $\alpha$-SMA and collagen I $\alpha$ (Figure 4A).

The significance of putative molecular effectors, modulating HSC activation downstream PHD1, was also assessed. Of interest, transcript levels of distinct HIF target genes, such as vascular endothelial growth factor and plasminogen activator inhibitor 1 , were not significantly altered in $\mathrm{PHD}^{-1-} \mathrm{HSCs}$ compared with corresponding WT cells (Figure 4A). Expression levels of prolyl-4hydroxylase $\alpha 1$ and prolyl-4-hydroxylase $\alpha 2$, which represent procollagen-proline dioxygenases involved in collagen metabolism that are up-regulated by hypoxia in HSCs, were likewise unaltered in $\mathrm{PHD}^{-l-}$ HSCs (Figure 4A). Consistently, enzyme-linked immunosorbent assay measurements revealed no significant differences regarding normoxic or hypoxic stabilization of HIF-1 $\alpha$ protein in WT and PHD1 ${ }^{-l-}$ HSCs (Figure 4B).

Collectively, these analyses indicated that loss of PHD1 gene function attenuated HSC activation in a HIF1 -independent manner.

\section{Hepatic PHD1 Expression Correlates with Severity of Liver Fibrosis in Human Patients}

To assess whether PHD1 was likewise associated with the severity of liver fibrosis in human patients, its expression was determined in liver resection specimens from patients with absent or with mild (classified as Desmet score 0/1), with moderate (classified as Desmet score 2/3), or with severe liver fibrosis (classified as Desmet score 4). ${ }^{26}$

RT-qPCR analysis of whole liver lysates revealed that hepatic expression of PHD1 transcripts was significantly higher in patients with severe liver fibrosis (Desmet stage 4) than in patients who displayed only moderate (Desmet score 2/3) or no fibrosis (Desmet score 0/1) (Figure 5A), whereas PHD2 and PHD3 transcript levels decreased or were not affected, respectively (Figure 5B). Consistently, abundant expression of PHD1 protein could be detected by immunohistochemistry in liver samples from patients with severe fibrosis (Desmet score 4) but not in samples from patients with nonfibrotic livers (Desmet score 0) (Figure 5C). Remarkably, within fibrotic livers, spatial expression of PHD1 protein was not only detected in 
hepatocytes but was also likewise detected in dispersed spindle-like cells, which appeared to be myofibroblasts (Figure 5C). Indeed, immunohistochemical doublelabeling revealed that these PHD1-positive cells coexpressed $\alpha$-SMA, identifying them as activated HSCs or myofibroblasts (Figure 5D). ${ }^{27}$

Overall, these findings indicated that PHD1 was likewise implicated in human liver fibrosis, thus underlining the
A

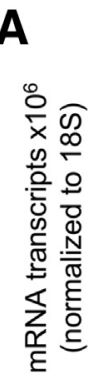

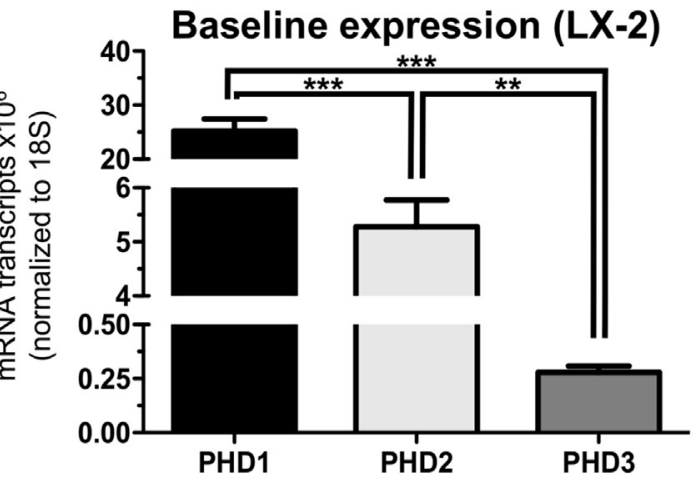

C

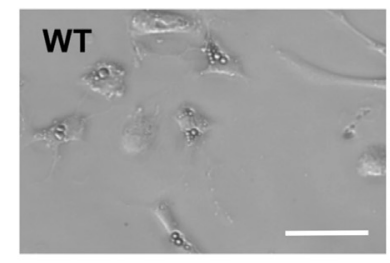

d1

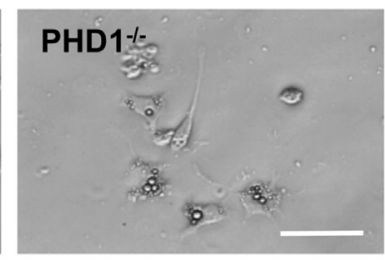

d5
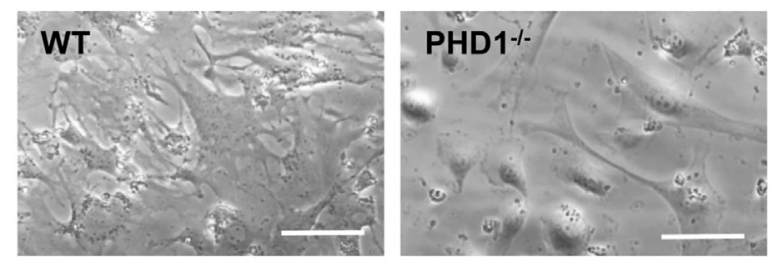

B
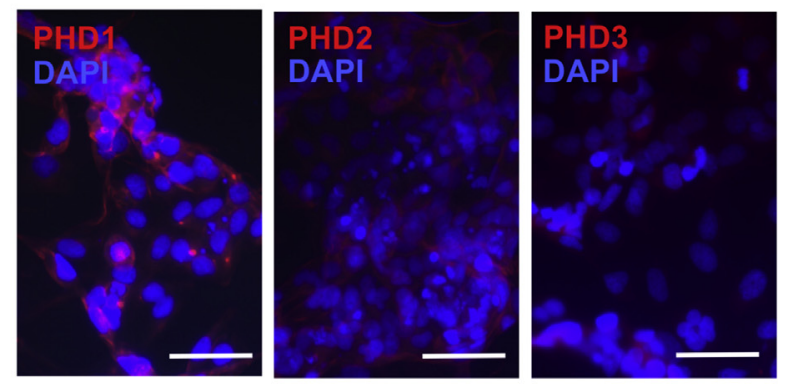

GFAP (d1)
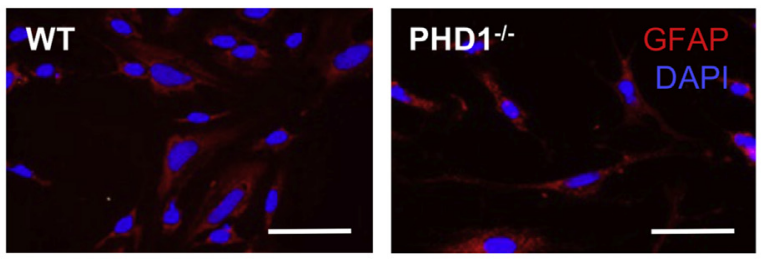

$\alpha$-SMA (d7)
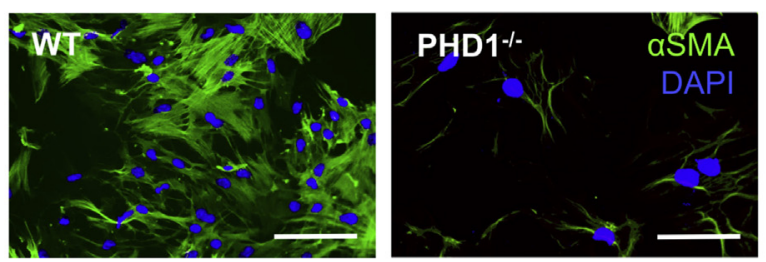

Migratory potential

$\mathbf{E}$

Migratory potential

(MEF)
Migratory potential

(NIH-3T3)
$(\mathrm{LX}-2)$
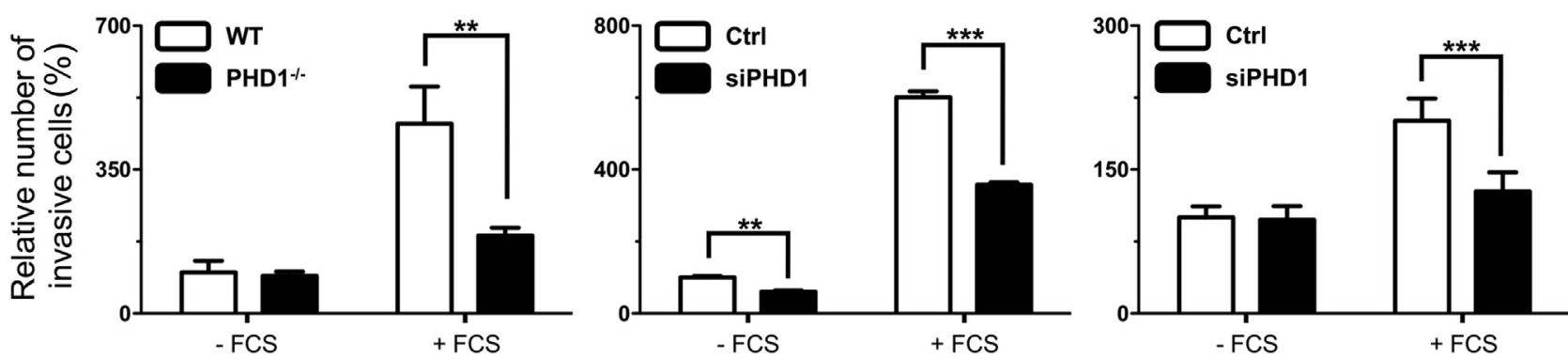

Figure 3 Prolyl-hydroxylase 1 (PHD1) deficiency attenuated profibrogenic properties of hepatic stellate cells (HSCs) and motility of fibrogenic cells in vitro. A: Quantitative RT-PCR analysis revealed that PHD1 was more abundantly expressed than PHD2 or PHD3 in the human LX-2 HSC cell line. B: Representative images of immunocytochemistry for PHD1, PHD2, and PHD3 (red) and DAPI (cell nuclei, blue) confirmed abundant expression of PHD1 but not PHD2 or PHD3 protein in human LX-2 HSCs. C: Representative images of microscopy and cytochemistry for glial fibrillary acidic protein (GFAP; marker of un-activated HSCs, red) and DAPI (cell nuclei, blue) of primary HSCs isolated from wild-type (WT) or PHD1 ${ }^{-1}$ mice and cultured for 1 day. Note comparable morphologic appearance and GFAP expression of WT and PHD1 ${ }^{-1-}$ HSCs. D: Representative images of microscopy and cytochemistry for $\alpha$-smooth muscle actin ( $\alpha$-SMA; myofibroblast marker, green) and DAPI (cell nuclei, blue) of primary HSCs isolated from WT or PHD1 ${ }^{-1-}$ mice and maintained in culture for 5 or 7 days. Note less myofibroblast-like morphology and attenuated $\alpha$-SMA expression of PHD1 ${ }^{-/-}$HSCs. E: Matrigel assays revealed the migratory potential of primary mouse embryonic fibroblasts (MEFs) isolated from WT and PHD1 ${ }^{-1-}$ mice, mouse NIH-3T3 fibroblasts with silenced PHD1 expression (siPHD1) versus controltransfected cells (Ctrl), and human LX-2 HSCs with siPHD1 versus Ctrl cells. Note that migratory potential on stimulation with fetal calf serum (FCS) was consistently impaired in PHD1-deficient or -underexpressing cells. Data are expressed as means \pm SEM. $n=3$ mice (A); $n=1$ of 3 representative experiments (E). ${ }^{* *} P<0.01,{ }^{* * *} P<0.001$. Scale bars $=50 \mu \mathrm{m}$ (B, C, and $\left.\mathbf{D}\right)$. 

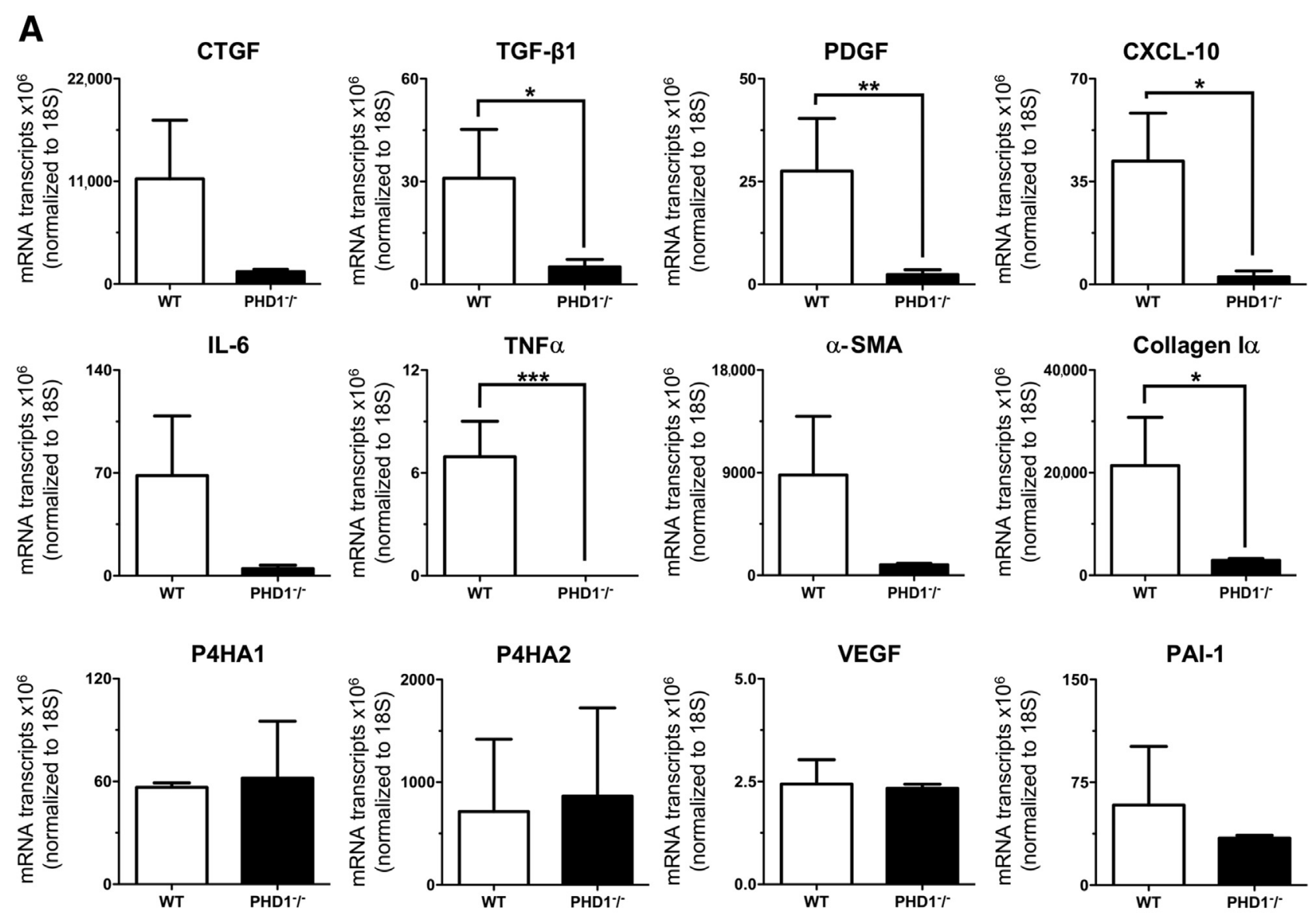

B

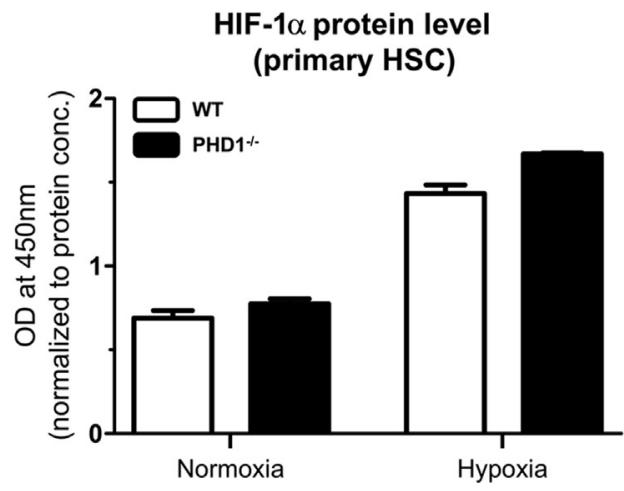

Figure 4 Prolyl-hydroxylase 1 (PHD1) deficiency altered the expression of cytokines involved in hepatic stellate cell (HSC) activation. A: Quantitative RT-PCR analyses of HSCs isolated from wild-type (WT) or $\mathrm{PHD}^{-1-}$ mice revealed attenuated expression of profibrogenic or promitogenic cytokines [connective tissue growth factor (CTGF), transforming growth factor (TGF)- $\beta 1$, platelet-derived growth factor (PDGF), chemokine (C-X-C motif) ligand (CXCL)-10, IL-6, tumor necrosis factor (TNF)- $\alpha$ )] and myofibroblast markers $[\alpha$-smooth muscle actin ( $\alpha$-SMA), collagen I $\alpha$ ]. By contrast, transcript levels of prolyl-4-hydroxylase $\alpha 1$ (P4HA1), prolyl-4-hydroxylase $\alpha 2$ (P4HA2), vascular endothelial growth factor (VEGF), or plasminogen activator inhibitor (PAI)-1 were not affected by PHD1 deficiency. B: Enzyme-linked immunosorbent assay-based detection of hypoxiainducible transcription factor (HIF)- $1 \alpha$ protein levels in nuclear lysates from WT and $\mathrm{PHD1}^{-1-} \mathrm{HSCS}$ revealed unaltered HIF- $1 \alpha$ protein levels under normoxic and hypoxic culture conditions. Data are expressed as means \pm SEM. $n=3$ mice per group. ${ }^{*} P<0.05,{ }^{* *} P<0.01$, and ${ }^{* *} P<0.001$. Conc, concentration. putative relevance of its fibrogenic effects in clinical practice.

\section{Discussion}

Here, we demonstrate that genetic loss of the HIF prolylhydroxylase (PHD) 1 protects against liver fibrosis in a mouse model of xenobiotic-induced bile duct injury without inducing HIF- $1 \alpha$ protein levels. These findings collectively hint at a specific and pathologically relevant function of the PHD1 oxygen sensor in HSCs, which triggers the development of biliary fibrosis in the applied animal model. ${ }^{6}$ It was also shown that HSCs within fibrotic human livers express PHD1 and that hepatic PHD1 expression correlates with the severity of liver fibrosis in human patients, indicating the putative clinical relevance of these findings.

Because liver fibrosis was not investigated in mice lacking PHD1 selectively in HSCs, it cannot be ruled out that other cell types likewise contribute to reduced biliary fibrosis in globally PHD1-deficient mice, which were used 

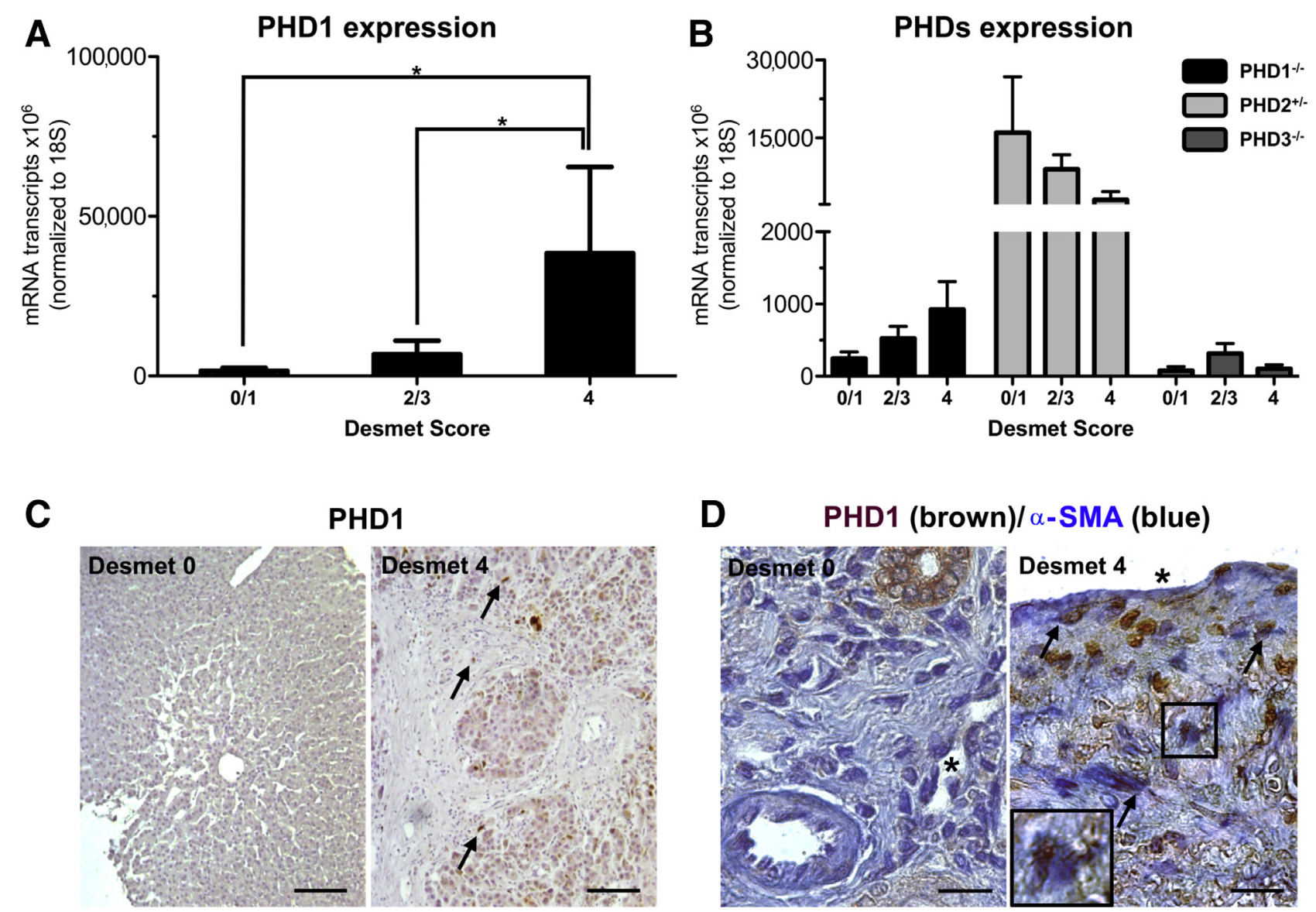

Figure 5 Significance of prolyl-hydroxylase 1 (PHD1) expression in human liver fibrosis. A: Quantitative RT-PCR analysis revealed PHD1 mRNA expression levels in liver tissue from patients with absent/mild (Desmet score 0/1), moderate (Desmet score 2/3), or severe (Desmet score 4) liver fibrosis. Note that PHD1 expression was increased with disease severity. B: RT-qPCR analysis of PHD1, PHD2, and PHD3 mRNA expression levels in liver tissue of an additional patient cohort with absent/mild (Desmet score 0/1), moderate (Desmet score 2/3), or severe (Desmet score 4) liver fibrosis. Note that expression of PHD1, but not PHD2 or PHD3 transcripts, was increased with disease severity. C: Representative images of PHD1 immunostaining revealed abundant expression of PHD1 protein in livers from patients with severe liver fibrosis (Desmet 4) but not in healthy livers (Desmet 0). Note PHD1 expression in putative periportal myofibroblasts (arrows). D: Representative images of immunhistochemistry double staining of periportal regions from healthy (Desmet 0) and fibrotic (Desmet 4) tissues for PHD1 (brown) and $\alpha$-smooth muscle actin ( $\alpha$-SMA; myofibroblast marker, blue). Note PHD1 expression in myofibroblasts (arrows and inset). Asterisks indicate portal vein branches. Boxed area is shown at higher magnification in the inset. Data are expressed as means \pm SEM. $n=22$ patients with absent/mild liver fibrosis $(\mathbf{A}) ; n=28$ patients with moderate liver fibrosis $(\mathbf{A}) ; n=10$ patients with severe liver fibrosis (A); $n=9$ patients with absent/mild liver fibrosis $(\mathbf{B}) ; n=7$ patients with moderate liver fibrosis $(\mathbf{B}) ; n=5$ patients with severe liver fibrosis (B). ${ }^{*} P<0.05$. Scale bars $=100 \mu \mathrm{m}$ (C); $50 \mu \mathrm{m}$ (D).

in this study. Indeed, previous analyses revealed that PHD1 deficiency alleviates hepatic ischemia/reperfusion injury ${ }^{18}$ and promotes liver regeneration after surgical resection. ${ }^{19,20}$ Moreover, it has been shown that loss of PHD1 conveys attenuated apoptosis of hepatocytes, most probably by increasing basal NF- $\mathrm{KB}$ activity. ${ }^{34}$ Mechanistically, these beneficial effects were attributable to loss of PHD1 in the hepatocytes themselves, rather than in other resident liver cells. Although it is likely that hepatocyte-specific effects of PHD1 deficiency support the phenotype described in this study, the present work unravels the HSC as a major player, conveying protective effects of PHD1 deficiency against biliary fibrosis. Indeed, HSCs represent the key trigger of liver fibrosis ${ }^{35}$ and give rise to an overwhelming majority of collagen-producing cells. ${ }^{3}$ In this study, attenuated biliary fibrosis of $\mathrm{PHD}^{-1-}$ livers was accompanied by significantly reduced accumulation of HSCs and, likely as a consequence, ${ }^{1,36}$ attenuated recruitment of proinflammatory cells.

The notion that the HSC represents the crucial cell type, mediating attenuated fibrosis in PHD1-deficient mice, is in accordance with several reports, highlighting the relevance of HSC activation and differentiation into myofibroblasts in the pathogenesis of liver fibrosis. ${ }^{1,31,37,38}$ The in vitro analyses presented in this study indicate that loss of PHD1 effectively interferes with these processes. For instance, the expression of the myofibroblast marker, $\alpha$-SMA, was significantly reduced in differentiating cultures of PHD1-deficient HSCs. HSC activation, which is reflected by expression of $\alpha$-SMA, is mainly driven by TGF- $\beta$ and by platelet-derived growth factor. ${ }^{1,31}$ Of note, both cytokines can be secreted by HSCs in an autocrine fashion to 
maintain profibrotic activation., ${ }^{4,31}$ Remarkably, it was found that expression levels of TGF- $\beta$ and platelet-derived growth factor were significantly reduced in PHD1deficient HSCs, along with similarly attenuated expression of various other cytokines involved in proliferation and migration of HSCs. Previous studies have shown that apoptosis of activated HSCs, ${ }^{39}$ but also their deactivation to a quiescent state, result in the resolution of liver fibrosis. ${ }^{40}$ It is in this context conceivable that PHD1 deficiency interferes with continued profibrotic signaling of activated HSCs, thus facilitating resolution of liver fibrosis.

It remains tempting to speculate on the molecular pathways behind these effects of PHD1 deficiency on HSC activation. Given the well-documented interplay between PHD1 and NF- $\kappa B,{ }^{34}$ as well as the key significance of the NF- $\kappa B$ pathway in liver fibrosis ${ }^{41}$ it appears likely that NF- $\kappa \mathrm{B}$ is involved. The net effect of increased $\mathrm{NF}-\kappa \mathrm{B}$ activity in HSCs could be assumed to be profibrogenic, which appears inconsistent with these findings of decreased HSC activation in PHD1-deficient mice. ${ }^{41}$ $\mathrm{NF}-\kappa \mathrm{B}$ does, however, appear to play a dual role, especially in experimental models of chronic liver injury

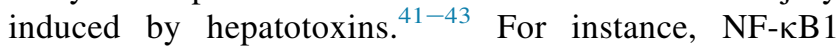
(p50)-deficient mice develop more severe neutrophilic inflammation and fibrosis than WT littermates in a model of chronic liver injury induced by the hepatotoxin carbon tetrachloride. ${ }^{43}$

Previous studies have highlighted the significance of hypoxia in liver fibrosis and, more specifically, delineated a profibrotic role of the HIFs in its development. ${ }^{8,16}$ Indeed, hypoxia levels are reportedly increased in fibrotic liver tissue, ${ }^{8}$ and interference with HIF- $1 \alpha$ and HIF- $2 \alpha$ stabilization by forced expression of von HippelLindau protein attenuates hepatic fibrosis in mice. ${ }^{16}$ At first glance, it might thus appear paradoxical that global deletion of PHD1, which reportedly enhances hepatocellular HIF- $2 \alpha$ (and to a lesser extent HIF- $1 \alpha$ ) levels, ${ }^{18}$ has opposite effects. However, the present study reveals that loss of PHD1 was not accompanied by an increase of HIF- $1 \alpha$ protein levels in HSCs. The observed hepatoprotective effects conferred by PHD1 deficiency in HSCs thus seem to be HIF-1 independent. Even in the event that loss of PHD1 induces HIF stabilization in other cell types than HSCs, these observations may be explicable by peculiarities related to the specific animal models that were applied to mimic chronic liver disease in these different studies. In particular, the antifibrotic functions of PHD1 deficiency in HSCs, which are outlined in the present study, may overshadow putatively opposite effects of HIF stabilization in hepatocytes and other resident liver cells. In fact, HSC activity plays a more prominent role in the DDC-induced model of biliary fibrosis, which was applied in this study, than in models of chronic bile duct ligation, which were applied in previous studies to address the significance of HIF in liver fibrosis. ${ }^{8,16}$ It is in this context noteworthy that chronic feeding with the xenobiotic DDC causes pericholangitis and consecutive biliary liver fibrosis in mice ${ }^{5,6}$ and that the preclinical findings obtained in the present study might thus bear particular relevance about forms of human biliary liver fibrosis that are associated with sclerosing cholangitis.

Obviously, caution is warranted when speculating on the putative clinical significance of the present findings, which were generated in a transgenic mouse model. For instance, mice and humans differ substantially regarding specific proportions and absolute numbers of host immune cells that are present within the liver. ${ }^{5}$ Moreover, the genetic background of the applied transgenic mice may affect the responsiveness of the host immune system to toxic stimuli, such as DDC feeding. ${ }^{5,44,45}$ Of importance, the in vivo results, which were obtained in constitutively PHD1-deficient mice, may be biased by direct or indirect effects of global PHD1 deficiency on DDC metabolism, resulting in overall decreased DDC toxicity to the biliary system. In fact, the accumulation of biliary porphyrin pigment plugs, which represent a key trigger of liver fibrosis in the applied mouse model, ${ }^{6,46}$ was significantly attenuated in DDC-treated PHD1 $1^{-l-}$ animals compared with WT littermates. It cannot be ruled out that reduced formation of porphyrin plugs is causally involved in the observed phenotype, regardless of the effects of PHD1 deficiency on HSC activation that was documented in vitro.

Given these shortcomings, it was important to obtain some initial evidence, indicating the putative significance of PHD1 in human liver fibrosis. Of importance, it was shown that PHD1 protein is not only abundantly expressed in human HSCs in vitro but likewise in resident HSCs of patients with liver fibrosis. Most strikingly, however, hepatic PHD1 (but not PHD2 or PHD3) expression levels correlated with the extent of liver fibrosis in human patients, raising the intriguing possibility that increased PHD1 enzyme activity in HSCs may contribute to the progression of human fibrotic liver disease through stimulating sustained HSC activation and myofibroblast differentiation. This would open a promising door for therapeutic intervention, because pharmacologic small-molecule PHD enzyme inhibitors are already available, and putative clinical applications for these drugs are currently highly investigated by translational researchers and pharmaceutical companies. ${ }^{14}$ In fact, it could recently be shown that pharmacologic pan-hydroxlase inhibition significantly attenuated the development of intestinal fibrosis in mice exposed to experimental colitis. ${ }^{47}$ However, because most of these drugs are neither specific for the oxygen-sensing PHD enzymes (PHD1, PHD2, and PHD3) nor for distinct cell populations, it remains to be investigated whether pharmacologic PHD enzyme inhibitors can be applied to rather specifically target PHD1 in HSCs. 


\section{Conclusion}

This study unravels the promotion and maintenance of profibrotic HSC functions as a novel function of the PHD1 oxygen sensor and indicates that interference with PHD1 enzyme function may be of therapeutic value to counteract the pathogenesis and progression of biliary liver fibrosis.

\section{Supplemental Data}

Supplemental material for this article can be found at https://doi.org/10.1016/j.ajpath.2018.08.003.

\section{References}

1. Bataller R, Brenner DA: Liver fibrosis. J Clin Invest 2005, 115 : 209-218

2. O'Leary JG, Lepe R, Davis GL: Indications for liver transplantation. Gastroenterology 2008, 134:1764-1776

3. Mederacke I, Hsu CC, Troeger JS, Huebener P, Mu X, Dapito DH, Pradere J-P, Schwabe RF: Fate tracing reveals hepatic stellate cells as dominant contributors to liver fibrosis independent of its aetiology. Nat Commun 2013, 4:2823

4. Lee UE, Friedman SL: Mechanisms of hepatic fibrogenesis. Best Pract Res Clin Gastroenterol 2011, 25:195-206

5. Liedtke C, Luedde T, Sauerbruch T, Scholten D, Streetz K, Tacke F, Tolba R, Trautwein C, Trebicka J, Weiskirchen R: Experimental liver fibrosis research: update on animal models, legal issues and translational aspects. Fibrogenesis Tissue Repair 2013, 6:19

6. Fickert P, Stöger U, Fuchsbichler A, Moustafa T, Marschall H-U, Weiglein AH, Tsybrovskyy O, Jaeschke H, Zatloukal K, Denk H, Trauner M: A new xenobiotic-induced mouse model of sclerosing cholangitis and biliary fibrosis. Am J Pathol 2007, 171:525-536

7. Copple BL, Bai S, Moon J-O: Hypoxia-inducible factor-dependent production of profibrotic mediators by hypoxic Kupffer cells. Hepatol Res 2010, 40:530-539

8. Moon J-O, Welch TP, Gonzalez FJ, Copple BL: Reduced liver fibrosis in hypoxia-inducible factor-1alpha-deficient mice. Am J Physiol Gastrointest Liver Physiol 2009, 296:G582-G592

9. Ji S, Lemasters JJ, Christenson V, Thurman RG: Periportal and pericentral pyridine nucleotide fluorescence from the surface of the perfused liver: evaluation of the hypothesis that chronic treatment with ethanol produces pericentral hypoxia. Proc Natl Acad Sci U S A 1982, 79:5415-5419

10. Semenza GL: Targeting HIF-1 for cancer therapy. Nat Rev Cancer 2003, 3:721-732

11. Kaelin WG Jr, Ratcliffe PJ: Oxygen sensing by metazoans: the central role of the HIF hydroxylase pathway. Mol Cell 2008, 30:393-402

12. Semenza GL: Oxygen sensing, hypoxia-inducible factors, and disease pathophysiology. Annu Rev Pathol 2014, 9:47-71

13. Fong G-H, Takeda K: Role and regulation of prolyl hydroxylase domain proteins. Cell Death Differ 2008, 15:635-641

14. Harnoss JM, Strowitzki MJ, Radhakrishnan P, Platzer LK, Harnoss JC, Hank T, Cai J, Ulrich A, Schneider M: Therapeutic inhibition of prolyl hydroxylase domain-containing enzymes in surgery: putative applications and challenges. Hypoxia (Auckl) 2015, 3:1-14

15. Bozova S, Elpek GO: Hypoxia-inducible factor-1alpha expression in experimental cirrhosis: correlation with vascular endothelial growth factor expression and angiogenesis. APMIS 2007, 115:795-801

16. Wang J, Lu Z, Xu Z, Tian P, Miao H, Pan S, Song R, Sun X, Zhao B, Wang D, Ma Y, Song X, Zhang S, Liu L, Jiang H: Reduction of hepatic fibrosis by overexpression of von Hippel-Lindau protein in experimental models of chronic liver disease. Sci Rep 2017, 7:41038
17. Kennel KB, Burmeister J, Schneider M, Taylor CT: The PHD1 oxygen sensor in health and disease. J Physiol 2018, 596:3899-3913

18. Schneider M, Van Geyte K, Fraisl P, Kiss J, Aragonés J, Mazzone M, Mairbäurl H, De Bock K, Jeoung NH, Mollenhauer M, Georgiadou M, Bishop T, Roncal C, Sutherland A, Jordan B, Gallez B, Weitz J, Harris RA, Maxwell P, Baes M, Ratcliffe P, Carmeliet P: Loss or silencing of the PHD1 prolyl hydroxylase protects livers of mice against ischemia/reperfusion injury. Gastroenterology 2010, 138: 1143-1154.e2

19. Mollenhauer M, Kiss J, Dudda J, Kirchberg J, Rahbari N, Radhakrishnan P, Niemietz T, Rausch V, Weitz J, Schneider M: Deficiency of the oxygen sensor PHD1 augments liver regeneration after partial hepatectomy. Langenbecks Arch Surg 2012, 397: $1313-1322$

20. Harnoss JM, Platzer LK, Burhenne J, Radhakrishnan P, Cai J, Strowitzki MJ, Weiss J, Ritter AS, Mollenhauer M, Schmidt T, Ulrich A, Haefeli WE, Schneider M: Prolyl hydroxylase inhibition enhances liver regeneration without induction of tumor growth. Ann Surg 2017, 265:782-791

21. Schadde E, Tsatsaris C, Swiderska-Syn M, Breitenstein S, Urner M, Schimmer R, Booy C, Z'graggen BR, Wenger RH, Spahn DR, Hertl M, Knechtle S, Diehl AM, Schläpfer M, Beck-Schimmer B: Hypoxia of the growing liver accelerates regeneration. Surgery 2017, 161:666-679

22. Committee for the Update of the Guide for the Care and Use of Laboratory Animals; National Research Council: Guide for the Care and Use of Laboratory Animals: Eighth Edition. Washington, DC, National Academies Press, 2011

23. Aragonés J, Schneider M, Van Geyte K, Fraisl P, Dresselaers T, Mazzone M, et al: Deficiency or inhibition of oxygen sensor Phd1 induces hypoxia tolerance by reprogramming basal metabolism. Nat Genet 2008, 40:170-180

24. Nagy ZB, Wichmann B, Kalmár A, Barták BK, Tulassay Z, Molnár B: miRNA isolation from FFPET specimen: a technical comparison of miRNA and total RNA isolation methods. Pathol Oncol Res 2016, 22: $505-513$

25. Liu W, Hou Y, Chen H, Wei H, Lin W, Li J, Zhang M, He F, Jiang Y: Sample preparation method for isolation of single-cell types from mouse liver for proteomic studies. Proteomics 2011, 11:3556-3564

26. Desmet VJ, Gerber M, Hoofnagle JH, Manns M, Scheuer PJ: Classification of chronic hepatitis: diagnosis, grading and staging. Hepatology 1994, 19:1513-1520

27. Novo E, di Bonzo LV, Cannito S, Colombatto S, Parola M: Hepatic myofibroblasts: a heterogeneous population of multifunctional cells in liver fibrogenesis. Int J Biochem Cell Biol 2009, 41:2089-2093

28. Wilhelm A, Aldridge V, Haldar D, Naylor AJ, Weston CJ, Hedegaard D, Garg A, Fear J, Reynolds GM, Croft AP, Henderson NC, Buckley CD, Newsome PN: CD248/endosialin critically regulates hepatic stellate cell proliferation during chronic liver injury via a PDGF-regulated mechanism. Gut 2016, 65:1175-1185

29. Xu L, Hui AY, Albanis E, Arthur MJ, O’Byrne SM, Blaner WS, Mukherjee P, Friedman SL, Eng FJ: Human hepatic stellate cell lines, LX-1 and LX-2: new tools for analysis of hepatic fibrosis. Gut 2005, $54: 142-151$

30. Geerts A: History, heterogeneity, developmental biology, and functions of quiescent hepatic stellate cells. Semin Liver Dis 2001, 21 311-335

31. Friedman SL: Hepatic stellate cells: protean, multifunctional, and enigmatic cells of the liver. Physiol Rev 2008, 88:125-172

32. Liang YJ, Luo J, Lu Q, Zhou Y, Wu HW, Zheng D, Ren YY, Sun KY, Wang Y, Zhang ZS: Gene profile of chemokines on hepatic stellate cells of schistosome-infected mice and antifibrotic roles of CXCL9/10 on liver non-parenchymal cells. PLoS One 2012, 7: e42490

33. Hintermann E, Bayer M, Pfeilschifter JM, Luster AD, Christen U: CXCL10 promotes liver fibrosis by prevention of NK cell mediated hepatic stellate cell inactivation. J Autoimmun 2010, 35:424-435 
34. Fitzpatrick SF, Fábián Z, Schaible B, Lenihan CR, Schwarzl T, Rodriguez J, Zheng X, Li Z, Tambuwala MM, Higgins DG, O'Meara Y, Slattery C, Manresa MC, Fraisl P, Bruning U, Baes M, Carmeliet P, Doherty G, von Kriegsheim A, Cummins EP, Taylor CT: Prolyl hydroxylase-1 regulates hepatocyte apoptosis in an NF-kappaBdependent manner. Biochem Biophys Res Commun 2016, 474:579-586

35. Lua I, Li Y, Zagory JA, Wang KS, French SW, Sévigny J, Asahina K: Characterization of hepatic stellate cells, portal fibroblasts, and mesothelial cells in normal and fibrotic livers. J Hepatol 2016, 64: $1137-1146$

36. Viñas $\mathrm{O}$, Bataller $\mathrm{R}$, Sancho-Bru $\mathrm{P}$, Ginès $\mathrm{P}$, Berenguer $\mathrm{C}$, Enrich $\mathrm{C}$, Nicolás JM, Ercilla G, Gallart T, Vives J, Arroyo V, Rodés J: Human hepatic stellate cells show features of antigen-presenting cells and stimulate lymphocyte proliferation. Hepatology 2003, 38:919-929

37. Guyot C, Lepreux S, Combe C, Doudnikoff E, Bioulac-Sage P, Balabaud C, Desmoulière A: Hepatic fibrosis and cirrhosis: the (myo) fibroblastic cell subpopulations involved. Int J Biochem Cell Biol 2006, 38:135-151

38. Bataller R, Gasull X, Ginès P, Hellemans K, Görbig MN, Nicolás JM, Sancho-Bru P, De Las Heras D, Gual A, Geerts A, Arroyo V, Rodés J: In vitro and in vivo activation of rat hepatic stellate cells results in de novo expression of L-type voltage-operated calcium channels. Hepatology 2001, 33:956-962

39. Iredale JP, Benyon RC, Pickering J, McCullen M, Northrop M, Pawley S, Hovell C, Arthur MJ: Mechanisms of spontaneous resolution of rat liver fibrosis. Hepatic stellate cell apoptosis and reduced hepatic expression of metalloproteinase inhibitors. J Clin Invest 1998, 102:538-549

40. Troeger JS, Mederacke I, Gwak G, Dapito DH, Mu X, Hsu CC, Pradere J, Friedman RA, Schwabe RF: Deactivation of hepatic stellate cells during liver fibrosis resolution in mice. Gastroenterology 2012, 143:1073-1083.e22

41. Luedde T, Schwabe RF: NF-kappaB in the liver-linking injury, fibrosis and hepatocellular carcinoma. Nat Rev Gastroenterol Hepatol 2011, 8:108-118

42. Rippe RA, Schrum LW, Stefanovic B, Solís-Herruzo JA, Brenner DA: NF-kappaB inhibits expression of the alpha1(I) collagen gene. DNA Cell Biol 1999, 18:751-761

43. Oakley F, Mann J, Nailard S, Smart DE, Mungalsingh N, Constandinou C, Ali S, Wilson SJ, Millward-Sadler H, Iredale JP, Mann DA: Nuclear factor-kappaB1 (p50) limits the inflammatory and fibrogenic responses to chronic injury. Am J Pathol 2005, 166: 695-708

44. Weber S, Gressner OA, Hall R, Grünhage F, Lammert F: Genetic determinants in hepatic fibrosis: from experimental models to fibrogenic gene signatures in humans. Clin Liver Dis 2008, 12: 747-757

45. Walkin L, Herrick SE, Summers A, Brenchley PE, Hoff CM, Korstanje R, Margetts PJ: The role of mouse strain differences in the susceptibility to fibrosis: a systematic review. Fibrogenesis Tissue Repair 2013, 6:18

46. Fickert P, Trauner M, Fuchsbichler A, Stumptner C, Zatloukal K, Denk H: Bile acid-induced Mallory body formation in drug-primed mouse liver. Am J Pathol 2002, 161:2019-2026

47. Manresa MC, Tambuwala MM, Radhakrishnan P, Harnoss JM, Brown E, Cavadas MA, Keogh CE, Cheong A, Barrett KE, Cummins EP, Schneider M, Taylor CT: Hydroxylases regulate intestinal fibrosis through the suppression of ERK-mediated TGF-betal signaling. Am J Physiol Gastrointest Liver Physiol 2016, 311: G1076-G1090 